\title{
Evaluation of the Impact of the Kuwait Diabetes Care Program on the Quality of Diabetes Care
}

\author{
Afaf Al-Adsani ${ }^{a, b}$ Jamila Al-Faraj ${ }^{a}$ Fatma Al-Sultan ${ }^{a}$ Mohamed El-Feky ${ }^{a}$ \\ Nouria Al-Mezel ${ }^{a}$ Wafik Saba ${ }^{a}$ Sharifa Aljassar ${ }^{a}$ \\ aWorking Group of the Diabetes Care Program, Central Department of Primary Health Care, Ministry of Health, \\ ${ }^{b}$ Diabetes Unit, Department of Medicine, Al-Sabah Hospital, Kuwait
}

\section{Key Words}

Diabetes · Primary care - Quality of care · Kuwait

\begin{abstract}
Objectives: To evaluate the impact of the Kuwait Diabetes Care Program on the quality of care provided for diabetic patients in the Primary Health Care setting. Materials and Methods: The Kuwait Diabetes Care Program developed, published and disseminated clinical practice guidelines, conducted training courses, standards for diabetes care, and introduced a monitoring and evaluation system. Four audits (September 1999, October 2001, 2002 and 2003) were carried out at five diabetic clinics. September 1999 referred to in this study as first (baseline) audit was prior to the introduction of the clinical practice guidelines. The three other audits were performed to assess adherence with the guidelines in the administrative management of patients' records and implementation of the standards. Two hundred and fifty patients were involved in the study. Results: The proportion of patients with organized, structured files increased significantly from 60.0 to $100.0 \%$ ( $p<0.001)$, and recording of patients' demographic data increased from 38.6 to $95.6 \%$ ( $p<$ 0.001). Use of structured visit sheets, proper fixation of the laboratory and prescription sheets had also improved significantly. The prevalence of smoking assessment, fundus examination, and foot examination increased significantly
\end{abstract}

from 2.8 to $27.2 \%(p<0.001) ; 2.4$ to $31.6 \%(p<0.001) ; 0.4$ to $40.4 \%(p<0.001)$, respectively. The prevalence of measuring urinary microalbumin, serum creatinine and $\mathrm{HbA}_{1 c}$ increased significantly from 4.4 to $26.4 \%(\mathrm{p}<0.001) ; 16.0$ to $78.4 \%$ ( $p<$ $0.001)$, and 10.4 to $60.8 \%(p<0.001)$, respectively. The prevalence of measuring serum total cholesterol, triglycerides, $\mathrm{HDL}-\mathrm{C}$, and LDL-C levels increased significantly from 16.4 to $80.0 \%(p<0.001) ; 14.4$ to $80.0 \%(p<0.001) ; 2.4$ to $32.8 \%$ ( $p<$ $0.001)$, and 2.4 to $24.0 \%(p<0.001)$, respectively. Conclusion: This audit shows that a national diabetes program was associated with improved processes of diabetes care. Further, support from health authorities, provision of manpower resources, a continuing monitoring and evaluation system, and conduction of structured education programs may lead to further improvements in the quality of diabetes care.

Copyright $\odot 2007$ S. Karger AG, Basel

\section{Introduction}

Diabetes mellitus is a major health problem worldwide with a great impact on patient well-being and health care resources. Diabetic complications, such as coronary artery disease, peripheral vascular disease, stroke, diabetic neuropathy, renal failure and blindness, result in significant disability, reduce life expectancy and impose enormous health costs for virtually every society [1]. Commu-

\section{KARGER \\ Fax +41613061234 \\ E-Mail karger@karger.ch}

www.karger.com
(C) 2007 S. Karger AG, Basel

1011-7571/08/0171-0014\$24.50/0

Accessible online at:

www.karger.com/mpp
Dr. Afaf Al-Adsani

Diabetes Unit, Department of Medicine

Al-Sabah Hospital (Kuwait)

Tel. +965 4812000 ext. 4229, Fax +965 488 3418, E-Mail amsaladsani@yahoo.com 
nity-based studies have shown that well organized and structured diabetes care programs can improve the process and outcome of the care of diabetic populations [2, 3]. The World Health Organization has set guidelines and initiatives for national diabetes programs to improve the quality of diabetes care worldwide [4], and national diabetes programs have become extremely important in many countries as exemplified in the United Kingdom, where the National Service Framework for diabetes initiated a 10-year program in 2001 [5].

The socioeconomic development and changes in lifestyles in Kuwait have been accompanied by the emergence of diabetes as a major health problem [6]. The prevalence of type 2 diabetes has been reported to be approximately $15.0 \%$ [7]. The incidence of type 1 diabetes has increased nearly fivefold, from approximately 4.0 to 20.0 per 100,000, within the last two decades $[8,9]$. Diabetes care is largely provided at the primary care level through several mini-diabetic clinics distributed over five health regions. The Kuwait Diabetes Care Program (KDCP) (appendix) was established to improve the quality of care provided for diabetic patients in the Primary Health Care (PHC) setting throughout Kuwait. We carried out this study to evaluate the impact of KDCP on the quality of diabetes care.

\section{Materials and Methods}

Four cycles of audits were performed. The first baseline audit was conducted to evaluate the quality of diabetes care before the onset of the program (i.e. September 1999). Second, third, and fourth audits were performed in October 2001, 2002, and 2003, respectively. Five out of 21 centers with mini-diabetic clinics were selected, representing the five health regions. Centers with family medicine practice were not included in the study. The selection of the clinics was done under the sponsorship of the Central Department of Primary Health Care (CDPHC) because of other ongoing programs in these centers for other specialties. However, the selected diabetic clinics were not different from other clinics in terms of structure, patient load, availability of dieticians and nurses, availability of fundus camera or delivery of diabetes care, and they were not involved in other quality improvement programs or research that affects the findings. The working group were taught how to survey and collect data. Data collection was done simultaneously at the five diabetic clinics using designed sheets and 50 medical records were studied in each centre, thereby providing a total of 250 records for each audit. Because of organizational barriers, medical records were selected by convenience sampling for patients who attended the clinics from 1st of October to 30th of September for each audit year. Medical records were included only if the patients had had three or more visits during that year to ensure that the treating physician had enough time to implement the guidelines. The designed data collection sheets contained the items necessary to measure the structure of the clinic and the process of diabetes care. It was decided at the outset only to use process measures to audit the program initially, this being necessary because at baseline measurements such as for $\mathrm{HbA}_{1 \mathrm{c}}$ were not performed frequently enough to provide data and outcomes such as amputation and laser photocoagulation were not being recorded.

Scoring of data was in the form of yes or no to indicate the implementation of the standard. There was general agreement about the interpretation of the data from the medical records. Adherence of the patient to his appointment was measured at the survey period.

\section{Statistical Methods}

Data obtained from each audit are presented as percentages. The $\chi^{2}$ for linear trend was used to assess the significance of the trend in proportions between implementation of the standards in the four cycles of audits, and the data were compared between the baseline and the fourth audit. The normal Z-test was used to determine the significance of the difference between the first and fourth audits. The cut-off level for significance was $<0.05$.

\section{Results}

\section{Human Resources, Administrative Structure and}

Specialized Clinics for Diabetes Care

The manpower resources and access to specialized and laboratory services involved in diabetes care over the four periods in the studied clinics are summarized in table 1 . Shortage of physicians and lack of dieticians, diabetes nurses, educators, social workers and secretaries were the main deficiencies.

\section{The Impact of KDCP on the Process of Diabetes Care}

The changes in the process of administrative standards in diabetes services over the four periods are given in table 2. Although almost all patients have identity booklets with appointment dates registered, the adherence to appointment was not optimal (70.0-73.4\%) and did not improve. The availability of an appointment registry in the clinics improved, but there was no policy for defaulters. The filing system improved significantly from the baseline $(150 / 250,60 \%)$ to fourth audit $(250 / 250$, $100 \%$; $\mathrm{p}<0.001)$ and recording patients' identification data increased from $96 / 249$ (38.6\%) to $239 / 250$ (95.6\%; $\mathrm{p}<0.001)$. Use of structured visit sheets, proper fixation of the laboratory and prescription sheets had also improved significantly.

The improvements in the process of clinical diabetes care are shown in table 3 . There was a significant improvement in implementation of all the clinical standards. The prevalence of smoking assessment, fundus ex- 
Table 1. Manpower resources and access to specialized and laboratory services involved in diabetes care over the four periods in the studied clinics

\begin{tabular}{lllll}
\hline Measure & $\begin{array}{l}\text { First audit } \\
\text { (baseline) }\end{array}$ & $\begin{array}{l}\text { Second audit } \\
\text { Oct. 2001 }\end{array}$ & $\begin{array}{l}\text { Third audit } \\
\text { Oct. 2002 }\end{array}$ & $\begin{array}{l}\text { Fourth audit } \\
\text { Oct. 2003 }\end{array}$ \\
\hline $\begin{array}{l}\text { Total physicians } \\
\text { Total registered nurses }\end{array}$ & 15 & 14 & 14 & 14 \\
Availability of & 9 & 8 & 6 & 6 \\
$\quad$ Diabetes nurse & & & & 0 \\
$\quad$ Diabetes educator & 0 & 0 & 0 & 0 \\
$\quad$ Dietician & 0 & 0 & 0 & 1 \\
$\quad$ Social worker & 0 & 0 & 0 & 0 \\
$\quad$ Secretary & 0 & 0 & 0 & 0 \\
Presence of appointment registry & 0 & 1 & 1 & $4 / 5$ \\
Presence of policy for appointment and defaulters & $1 / 5$ & $1 / 5$ & $3 / 5$ & $1 / 5$ \\
Access to fundus clinic & $1 / 5$ & $1 / 5$ & $1 / 5$ & $5 / 5$ \\
Access to foot care clinic & $5 / 5$ & $5 / 5$ & $5 / 5$ & $5 / 5$ \\
Availability of glycosylated hemoglobin measurement & $3 / 5$ & $4 / 5$ & $5 / 5$ & $5 / 5$ \\
Availability of microalbumin measurement & $5 / 5$ & $5 / 5$ & $5 / 5$ & $5 / 5$ \\
\hline
\end{tabular}

Table 2. Changes in the process of administrative care in diabetes services over the four periods

\begin{tabular}{|c|c|c|c|c|c|c|}
\hline Measure & $\begin{array}{l}\text { First audit } \\
\text { (baseline) }\end{array}$ & $\begin{array}{l}\text { Second audit } \\
\text { Oct. } 2001\end{array}$ & $\begin{array}{l}\text { Third audit } \\
\text { Oct. } 2002\end{array}$ & $\begin{array}{l}\text { Fourth audit } \\
\text { Oct. } 2003\end{array}$ & $\begin{array}{l}\mathrm{p} \text { linear } \\
\text { trend }\end{array}$ & $\begin{array}{l}\mathrm{p} \text { for } \mathrm{A} 1 \\
\text { vs. A4 }\end{array}$ \\
\hline Appointment booklet & $250 / 250(100.0)$ & 249/259 (99.6) & $249 / 259(99.6)$ & $250 / 250(100.0)$ & NS & NS \\
\hline Adherence to appointment & $171 / 233(73.4)$ & $161 / 222(72.5)$ & $177 / 241(73.4)$ & $168 / 240(70.0)$ & NS & NS \\
\hline Presence of structured and organized file & $150 / 250(60.0)$ & $150 / 250(60.0)$ & $218 / 250(87.2)$ & $250 / 250(100.0)$ & $<0.001$ & $<0.001$ \\
\hline Patient's identification data & 96/249 (38.6) & $194 / 250(77.6)$ & $238 / 250(95.2)$ & $239 / 250(95.6)$ & $<0.001$ & $<0.001$ \\
\hline Annual visit sheet & - & $1 / 250(0.4)$ & $80 / 250(32.0)$ & $50 / 250(20.0)$ & & \\
\hline Laboratory sheets in the proper place & $72 / 249(28.9)$ & $67 / 250(26.8)$ & $126 / 250(50.4)$ & $228 / 250(91.2)$ & $<0.001$ & $<0.001$ \\
\hline Prescription sheet in the proper place & $102 / 249(41.0)$ & $125 / 250(50.0)$ & $245 / 250(98.0)$ & $250 / 250(100.0)$ & $<0.001$ & $<0.001$ \\
\hline
\end{tabular}

$\mathrm{A} 1=$ First audit; $\mathrm{A} 4=$ fourth audit. Figures in parentheses indicate percentages.

amination, and foot examination increased significantly from $7 / 250(2.8 \%)$ to $68 / 250$ (27.2\%; p < 0.001); $6 / 250$ $(2.4 \%)$ to $79 / 250(31.6 \% ; \mathrm{p}<0.001)$, and $1 / 250(0.4 \%)$ to 101/250 (40.4\%; $\mathrm{p}<0.001)$, respectively. The prevalence of measuring urinary microalbumin, serum creatinine, and $\mathrm{HbA}_{1 \mathrm{c}}$ increased significantly from $11 / 250$ (4.4\%) to $66 / 250$ (26.4\%; p < 0.001); 40/250 (16\%) to $196 / 250$ (78.4\%; $\mathrm{p}<0.001)$, and $26 / 250(10.4 \%)$ to $152 / 250$ (60.8\%; p < 0.001 ), respectively. The prevalence of measuring serum total cholesterol, triglycerides, HDL-C, and LDL-C levels increased significantly from 16.4 to $80.0 \%$ ( $<<0.001$ ); 14.4 to $80.0 \%(\mathrm{p}<0.001) ; 2.4$ to $32.8 \%(\mathrm{p}<0.001)$, and 2.4 to $24.0 \%$ ( $\mathrm{p}<0.001)$, respectively.
The Impact of the KDCP on the Process of Continuing Medical Education and Patients' Education Programs

Clinical practice guidelines for diabetes care were not available before the onset of the program and therefore the program has provided it in all the clinics. Continuing Medical Education (CME) activities for the medical staff were available in three of the five surveyed clinics at the first audit and they were available in the five clinics at the fourth audit. Educational activities for nursing staff were available in only one clinic at the first audit and improved to be available in three clinics at the fourth audit. Patients' education activities were available in one or two of the surveyed clinics, but the activities were single and not 
Table 3. Changes in the process of clinical care in diabetes services over the four periods

\begin{tabular}{|c|c|c|c|c|c|c|}
\hline Measure & $\begin{array}{l}\text { First audit } \\
\text { (baseline) }\end{array}$ & $\begin{array}{l}\text { Second audit } \\
\text { Oct. } 2001\end{array}$ & $\begin{array}{l}\text { Third audit } \\
\text { Oct. } 2002\end{array}$ & $\begin{array}{l}\text { Fourth audit } \\
\text { Oct. } 2003\end{array}$ & $\begin{array}{l}\mathrm{p} \text { linear } \\
\text { trend }\end{array}$ & $\begin{array}{l}\mathrm{p} \text { A1 } \\
\text { vs. A4 }\end{array}$ \\
\hline Assessment of smoking status & $7 / 250(2.8)$ & $29 / 250(11.6)$ & $5 / 250(2.0)$ & $68 / 250(27.2)$ & $<0.001$ & $<0.001$ \\
\hline Fundus examination & $6 / 250(2.4)$ & $17 / 250(6.8)$ & $25 / 250(10.0)$ & $79 / 250(31.6)$ & $<0.001$ & $<0.001$ \\
\hline Foot examination & $1 / 250(0.4)$ & $35 / 250(14)$ & $43 / 250(17.2)$ & $101 / 250(40.4)$ & $<0.001$ & $<0.001$ \\
\hline \multicolumn{7}{|l|}{ Measurement of } \\
\hline Microalbumin & $11 / 250(4.4)$ & $40 / 250(16.0)$ & $50 / 250(20.0)$ & $66 / 250(26.4)$ & $<0.001$ & $<0.001$ \\
\hline Serum creatinine & $40 / 250(16.0)$ & $105 / 250(42.0)$ & $127 / 250(50.8)$ & $196 / 250(78.4)$ & $<0.001$ & $<0.001$ \\
\hline Glycosylated hemoglobin & $26 / 250(10.4)$ & $76 / 250(30.4)$ & $89 / 250(35.6)$ & $152 / 250(60.8)$ & $<0.001$ & $<0.001$ \\
\hline Triglycerides & $36 / 250(14.4)$ & $112 / 250(44.8)$ & $144 / 249(57.8)$ & $200 / 250(80.0)$ & $<0.001$ & $<0.001$ \\
\hline Total cholesterol & $41 / 250(16.4)$ & $110 / 250(44.0)$ & $145 / 249(58.2)$ & $200 / 250(80.0)$ & $<0.001$ & $<0.001$ \\
\hline HDL cholesterol & $6 / 250(2.4)$ & $25 / 250(10.0)$ & $43 / 249(17.3)$ & $82 / 250(32.8)$ & $<0.001$ & $<0.001$ \\
\hline LDL cholesterol & $6 / 250(2.4)$ & $25 / 250(10.0)$ & $41 / 249(16.5)$ & $60 / 250(24.0)$ & $<0.001$ & $<0.001$ \\
\hline
\end{tabular}

Figures in parentheses indicate percentages.

structured or coupled with treatment programs. However, there were some educational leaflets and educational posters in all the clinics.

\section{Discussion}

The main finding of this study, based on several interventional strategies and continuing audits of diabetes care services, is the improvement in the process of diabetes care as reported previously $[2,3,10,11]$. Programs which used multiple intervention strategies consisting of provision of clinical guidelines, workshops and training, clear management structure, audit and feedback were more successful in effecting change $[2,3]$ than programs which used only consultation models and chart audits $[11,12]$. Our study demonstrated that the majority of the standards were not optimally achieved. Auditing for implementation of the standards done by others showed that although it was successful in changing the general process of care in the practice, it was unsuccessful in achieving the standards set for diabetes care [13], and that standard of care of diabetics by general practitioners was generally not optimal [14].

The importance of continuing audit of diabetes services to ensure the implementation of standards of care has already been recognized $[14,15]$. Reauditing in this study showed that KDCP was successful in changing all the items that constitute the process of clinical care similar to other studies $[2,3,11,12]$, but it was only partly successful in changing the structure of diabetes care and educational efforts consistent with other findings [3, 12]. Drake and Baumer [11] reported that there was difficulty in improving manpower resources and suggested that clinical governance might have a positive effect on rectifying service deficiencies. Our study revealed that there was no improvement in patients' adherence to appointments. Griffin [16] has suggested a number of strategies (including patient reminders and induction videos, logistical and administrative changes in the clinic, training in consultation skills for health professionals) that have the potential to decrease the number of defaulters.

The improvement in implementation of the clinical standards reported in our study could be partly attributed to the improvements in the filing system, the medical records, as well as the feedback to the physicians regarding the importance of documentation in the records. In addition, the recent introduction and use of fundus cameras in the PHC setting has contributed to the improvement of fundus examination.

The recent introduction of the CME system in the Ministry of Health has contributed largely to the improvement in conducting CME programs for the medical staff as well as for patients. Studies have shown that changing knowledge was not enough for improving care, but changing beliefs and attitudes is equally important in improving implementation of guidelines [17] and, therefore, resulting in improvement of the clinical management and education of diabetic patients. Structured education/treatment programs carried out by physicians, dieticians, and diabetes nurse educators have been shown to be effective in improving the knowledge and metabol- 
ic control, as well as in reducing hospitalization and amputation rates [18-20]. Therefore, the educational program must provide encouragement, use behavioral strategies, and be coupled with expert adjustment of medication to obtain the desired outcome.

There are several limitations to our study. It lacked proper control group, electronic filing system and structured visit sheets, which resulted in convenience sampling. In addition, laboratory measurements for lipid profile, $\mathrm{HbA}_{1 \mathrm{c}}$ and microalbuminuria were done only in hospital laboratories during the study period. This might have contributed to the shortfall in implementation of these standards. Several interventions were used in the KDCP and, therefore, it is difficult to know the effect of each one in isolation. Most importantly, we did not study the impact of the program on the outcome that would have necessitated the use of structured self-educational/treatment programs using specific behavior change strategies provided by nurses and other health professionals [18].

\section{Conclusion}

Our study has shown that a national diabetes program was associated with improved processes of diabetes care. However, it was only partly associated with changes in the structure and conducting educational programs. Support from health authorities, provision of manpower resources, continuous monitoring and evaluation system, and conduction of structured education programs may lead to further improvements in the quality of diabetes care.

\section{Acknowledgements}

Dr. Afaf Al-Adsani, chairperson of the KDCP, would like to thank all members of the working group for their cooperation. We would thank Dr. Yousif Al-Nissef, Dr. Laila Al-Dosari, Directors of PHC areas for their support, WHO experts Dr. Assaf Al-Assaf and Dr. Imad El-Kebbi for their contribution, Prof. Philip Home for his valuable comments on the manuscript. Prof. Mohamed Moussa for assistance in statistical analysis; all physicians in PHC for their cooperation to improve diabetes care and the secretarial staff in the CDPHC for assistance with the administrative work.

\section{Appendix}

Establishment of the KDCP

The KDCP was established in September 1999 by a ministerial decree under the auspices of the CDPHC. A working group was formed, which included a chairperson and five members, each representing a health region. The main goal of the program was to improve the quality of care provided for diabetic patients in the PHC setting throughout Kuwait. Subsequently, the general plan was developed [21]. The main strategies which were set to achieve this goal were (a) development, publication, and dissemination of clinical practice guidelines for diabetes care, (b) development and dissemination of standards for diabetes care, (c) conducting training courses, and (d) establishing a monitoring system to ensure implementation of these standards.

\section{Intervention Strategies}

The clinical practice guidelines for diabetes care were developed and distributed through the CDPHC to all clinics of the $\mathrm{PHC}$ regions. The developed guidelines included standards of care to enhance the practice of ordering $\mathrm{HbA}_{1 \mathrm{c}}$, urine microalbumin, serum creatinine and lipid profiles, in addition to the performance of fundus and foot examinations, and education about the health risks of smoking.

Twelve standards and several indicators of diabetes care were developed to be implemented in the diabetic clinics. The working group developed the following standards: proper appointment system, proper filing system, availability of diabetes care team, assessment of smoking status, fundus and foot examination, measurement of $\mathrm{HbA}_{1 \mathrm{c}}$, serum creatinine, lipid profile, and urinary microalbumin, conducting CME activities for physicians and nurses, and participation in patients' education. The standards were developed based on international recommendations [22$24]$, and main deficiencies observed in practice. The standards are mainly set to improve the structure and process of diabetes care. The standards and indicators are available from the authors on request.

Training courses for physicians working in PHC were conducted. Currently, primary care physicians $(n=806)$ in Kuwait consists of 573 general practitioners (GPs), 70 family medicine specialists, 73 generalists working in mini-diabetics clinics, and 90 in mini-gynecology and obstetrics clinics. The first training course was conducted from 31 March to 4 April 2001 for 59 physicians working in diabetic mini-clinics at PHC centers. The course was conducted over 5 days ( $3 \mathrm{~h}$ per day). The clinical practice guidelines, formats of visit sheets and the standards to be implemented were distributed during the course. The course covered the following subjects: standards of care for diabetic patients and indicators for measurement, definition of diabetes mellitus, status of diabetes in Kuwait, screening and classification of diabetes, type 1 and type 2 diabetes: etiology, pathogenesis, and treatment. The course also covered acute and chronic complications of diabetes such as hypoglycemia and hyperglycemic emergencies, diabetic retinopathy, nephropathy, neuropathy and diabetic foot, hypertension and macrovascular complications. Emphasis on glucose monitoring and guidelines for glycemic and lipid control were also discussed. The role of education, exercise, and medical nutritional therapy in diabetes was emphasized. The course also covered an update on oral antihyperglycemic agents, insulin therapy, and combination therapy.

Subsequent courses were conducted in cycles periodically for GPs working at the PHC. Each cycle accommodated about 80 GPs.
18

Med Princ Pract 2008;17:14-19
Al-Adsani/Al-Faraj/Al-Sultan/El-Feky/

Al-Mezel/Saba/Aljassar 


\section{References}

1 The Rising Global Burden of Diabetes; in Diabetes Atlas. Brussels, International Diabetes Federation, 2000.

$\checkmark 2$ McDermott R, Tulip F, Schmidt B, Sinha A: Sustaining better diabetes care in remote indigenous Australian communities. BMJ 2003;327:428-430.

3 Khattab MS, Al-Khaldi YM, Abolfotouh MA, Khan MY, Humaidi MA, Alakija W, AlTokhy M: Impact of a diabetic program in a family practice setting in Asir Region, Saudi Arabia. Diabetes Res 1998;33:115-127.

4 Gruber W, King H: The WHO national diabetes programme initiative. Diabetes Res Clin Pract 1996;34:S1-S6.

5 National Service Framework for Diabetes: Standards. London, Department of Health, 2001.

6 Diabetes mellitus in Kuwait: A Statistical Analysis. Kuwait, Department of Statistics and Medical Records, Ministry of Health, 1998.

7 Abdella N, Al-Arouj M, Al-Nakhi A, Al Assoussi A, Moussa M: Non-insulin dependent diabetes mellitus in Kuwait, prevalence rates and associated risk factors. Diabetes Res Clin Pract 1998;42:187-196.

$>8$ Taha TH, Moussa MAA, Rashid AR, Fenech FF: Diabetes mellitus in Kuwait. Incidence in the first 29 years of life. Diabetologia 1983; 25:306-308.
-9 Shaltout AA, Qabazard MA, Abdella NA, LaPorte RE, al Arouj M, Ben Nekhi A, Moussa MA, al Khawari MA: High Incidence of Childhood-Onset IDDM in Kuwait. Diabetes Care 1995;18:923-927.

10 Tunbridge FK, Millar JP, Schofield PJ, Spencer JA, Young G, Home PD: Diabetes care in general practice: an approach to audit of process and outcome. Br J Gen Pract 1993;43. 291-295.

11 Drake AJ, Baumer JH: Improved clinical practice but continuing service deficiencies following a regional audit of childhood diabetes mellitus. Arch Dis Child 2000;82:302304.

12 Walker EA, Wylie-Rosett J, Shamoon H, Engel S, Basch CE, Zybert P, Cypress M: Program development to prevent complications of diabetes. Diabetes Care 1995;18:12911293.

13 Dunn NR, Bough P: Standards of care of diabetic patients in a typical English community. Br J Gen Pract 1996;46:401-405.

14 Kemple TJ, Hayter SR: Audit of diabetes in general practice. BMJ 1991;302:451-453.

15 Williams DR, Home PD; Members of a Working Group of the Research Unit of the Royal College of Physicians and British Diabetic Association: A proposal for Continuing Audit of Diabetes Services. Diabet Med 1992;9:759-764.

16 Griffin SJ: Lost to follow-up: the problem of defaulters from diabetes clinics. Diabet Med 1998;15:S14-S24.
17 Larme A, Pugh J: Attitudes of primary care physicians toward diabetes: barriers to guideline implementation. Diabetes Care 1998;21:1391-1396.

18 Clement C: Diabetes self-management education. Diabetes Care 1995;15:1204-1214.

19 Van den Arend IJM, Stolk RP, Rutten GEHM, Schrijvers GJP: Education integrated into structured general practice care for type 2 diabetic patients results in sustained improvement of disease knowledge and selfcare. Diabet Med 2000;17:190-197.

20 Redhead J, Hussein A, Gedling P, McCulloch AJ: The effectiveness of a primary-carebased diabetes education service. Diabet Med 1993;10:672-675.

21 General Plan of Central Department of Primary Health Care and Its Programmes. Kuwait, Ministry of Health, 2000.

22 Management of Diabetes Mellitus, Standards of Care and Clinical Practice Guidelines. Alexandria, World Health Organization, Regional Office for the Eastern Mediterranean, Egypt, 1994.

23 American Diabetes Association: Clinical Practice Recommendations 2000. Diabetes Care 2000;23(suppl 1):S1-S116.

24 British Diabetic Association: Recommendations for the Management of Diabetes in Primary Care. Report No. 2, ed 2. London, British Diabetic Association, 1997. 